\title{
CONF- $950846--47$
}

\author{
SAN095.0782C \\ RECEIVED \\ OCT 111995 \\ OSTI
}

EXPERIMENTAL MEASUREMENTS OF SHOCK PROPERTIES OF STISHOVITE

\author{
M: D. Furnish ${ }^{1}$ and E. Ito ${ }^{2}$ \\ IExperimental Impact Physics Dept. 1433, Sandia National Laboratories, Albuquerque NM 87185-0821 and, \\ ${ }^{2}$ Okayama University, Okayama, Japan
}

We have synthesized, characterized and performed Hugoniot measurements on monolithic samples of stishovite. Synthesis was accomplished in a multianvil press with pyrophyllite gaskets and carbon heaters. The samples had densities ranging from 3.80 to 4.07 , corresponding to stishovite volume fractions of 0.7 to 0.87 , a range confirmed by NMR analysis. They had no significant impurities except less than $1 \%$ carbon. Samples $\sim 1 \mathrm{~mm}$ thick and $3 \mathrm{~mm}$ diameter were tested in reverse- and forward-ballistics modes on a two-stage light gas gun, using velocity interferometry diagnostics. Impact velocities ranged from 4.0 to $6.5 \mathrm{~km} / \mathrm{sec}$. Hugoniot stresses for the four successful tests ranged from 65 to $225 \mathrm{GPa}$. At higher stresses significant uncertainties arise due to impact tilt/ nonplanariy issues. Results are consistent with earlier predictions of the stishovite Hugoniot based on quartzcentered Hugoniot data, static-compression (diamond-anvil cell) data and hydrostatic multianvil cell data. Release behavior appears to be frozen. These results are remarkable in view of the small size of the samples used.

\section{BACKGROUND}

Stishovite is a dense, high pressure polymorph of silica $\left(\mathrm{SiO}_{2}\right)$. It has an ambient density of $4.3 \mathrm{Mg} / \mathrm{m}^{3}$, is stable at stress above $7.5 \mathrm{GPa}$ at room temperature, and is composed of a structure in which the silicon atoms are each surrounded by six oxygen atoms in an octahedral arrangement.

A high-pressure phase of quartz observed by Wackerle ${ }^{1}$ in shock wave experiments was identified as stishovite by McQueen et al. ${ }^{2}$ on the basis of its observed transition pressure $(-14 \mathrm{GPa})$ and density. McQueen et al. ${ }^{2}$ derived a Grüneisen ratio of V $(\partial \mathrm{P} / \partial \mathrm{EE})_{v}$ $\equiv \gamma_{0}=0.9$, a heat of formation relative to quartz of 1.5 $\times 10^{10} \mathrm{erg} / \mathrm{gm}$, and a bulk sound speed of $10 \mathrm{~km} / \mathrm{sec}$ for stishovite. This large heat of formation indicates why stishovite is so rarely found in nature under atmospheric conditions (found primarily at recent impact sites such as Meteor Crater, Arizona).

Grady et al. ${ }^{3}$ performed a set of experiments on shocked quartz using manganin gauges to measure stress histories, obtaining release information as well as Hugoniot states. Results from that study are shown in Figure 1, together with Hugoniots from other sources as noted. Interestingly, that and subsequent studies (e.g. Chhabildas and Miller ${ }^{5}$ ) showed that releases are "frozen" down to about $8 \mathrm{GPa}$, then a transition to a lower-density phase occurs.

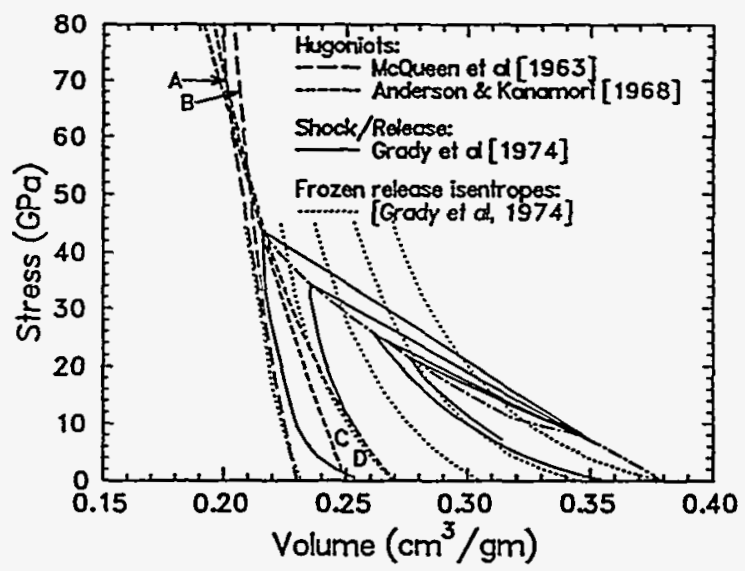

FIGURE 1. Summary of earlier experimental and theoretical studies. Curve " $A$ " is centered at $\rho_{0}=4.3 \mathrm{gm} / \mathrm{cm}^{3}\left(V_{0}=0.233\right.$ $\mathrm{cm}^{3} / \mathrm{gm}$ ); "B" at $2.65 \mathrm{gm} / \mathrm{cm}^{3} \mathrm{~V}_{0}=0.377 \mathrm{~cm}^{3} / \mathrm{gm}$ ) (McQueen et $\left.\mathrm{al}^{2}\right)$; "C" at $4.0 \mathrm{gm} / \mathrm{cm}^{3}\left(\mathrm{~V}_{0}=0.25 \mathrm{~cm}^{3} / \mathrm{gm}\right)$; and "D" at $3.7 \mathrm{gm} /$ $\mathrm{cm}^{3}\left(\mathrm{~V}_{0}=0.27 \mathrm{~cm}^{3} / \mathrm{gm}\right.$ ) (Anderson and Kanamori ${ }^{4}$ ). 


\section{DISCLAIMER}

This report was prepared as an account of work sponsored by an agency of the United States Government. Neither the United States Government nor any agency thereof, nor any of their employees, makes any warranty, express or implied, or assumes any legal liability or responsibility for the accuracy, completeness, or usefulness of any information, apparatus, product, or process disclosed, or represents that its use would not infringe privately owned rights. Reference herein to any specific commercial product, process, or service by trade name, trademark, manufacturer, or otherwise does not necessarily constitute or imply its endorsement, recommendation, or favoring by the United States Government or any agency thereof. The views and opinions of authors expressed herein do not necessarily state or reflect those of the United States Government or any agency thereof. 


\section{DISCLAIMER}

Portions of this document may be illegible in electronic image products. Images are produced from the best available original document. 
Prior to the present study, no shock compression studies using stishovite samples had been performed. The goal of the present study is to measure the Hugoniot of silica beginning with stishovite samples (initial densities of $3.8-4.2 \mathrm{Mg} / \mathrm{m}^{3}$ ). This is interesting for two reasons. First, the thermal regimes exercised are quite different than for a Hugoniot centered on quartz. Second, the starting material is known to be stishovite in the present experiments.

\section{SAMPLE PREPARATION AND CHARACTERIZATION}

Samples of monolithic, polycrystaliine stishovite (actually, a mixture of $\mathrm{SiO}_{2}$ polymorphs) were prepared in the laboratory of Hideyuki Fujisawa of the University of Tokyo. A multianvil press, with tungsten carbide anvils, pyrophyllite gasket and graphite heaters, was used. The starting material was an activated silica (a gel). The sample was held at $1100^{\circ} \mathrm{C}$ and $10 \mathrm{GPa}$ for slightly over an hour, with a slow cool-down. Two samples were prepared this way; one was recovered whole, while the other was recovered in six disks (apparently fractured during the cooling/ depressurization phase). The samples were about 3 $\mathrm{mm}$ diameter and $8 \mathrm{~mm}$ long. From this, samples about $1 \mathrm{~mm}$ thick and $3 \mathrm{~mm}$ diameter were obtained, and are shown in Figure 2.
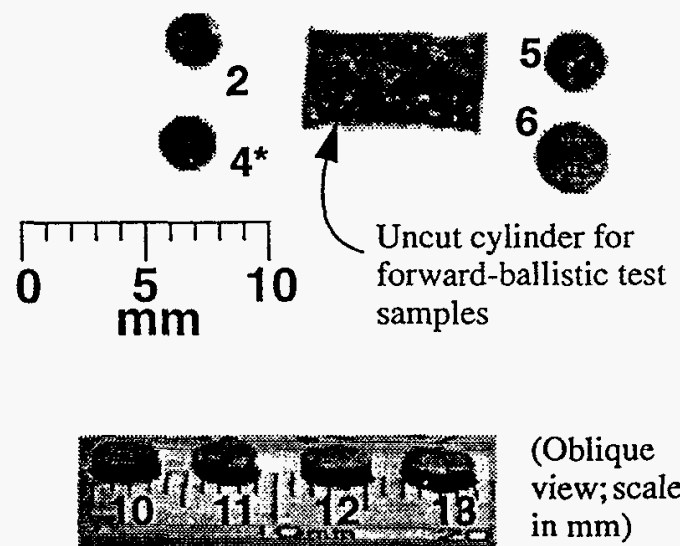

(Oblique view; scale in $\mathrm{mm}$ )

FIGURE 2. Stishovite samples used for present tests. Sample 4 was used for the successful reverse-ballistic test (ST-2); samples 11 - 13 were used for the successful forward-ballistic tests (ST$11,12,13$, respectively).
The samples were characterized by various methods, including visual examination, $\mathrm{X}$-ray fluorescence, density measurements, NMR, electron microprobe, $x$-ray imagery, ultrasonic measurements of sound velocities, and ultrasonic microscopy. The material studied appears to have a mass fraction of 80 $91 \%$ stishovite (balance quartz/coesite). Electron microprobe and $\mathrm{X}$-ray fluorescence characterizations showed minor carbon contamination $(<1 \%)$, with no other significant impurities.

\section{IMPACT EXPERIMENTS CONDUCTED}

Although a total of 14 tests were performed ( 8 with stishovite samples), only 4 tests were found to provide useful data on stishovite. Three utilized a transmittedsave (forward-ballistic) configuration (Figure 3), while the fourth utilized a reverse-ballistic configuration (Figure 4). Selected parameters for these tests are shown in Table 1.
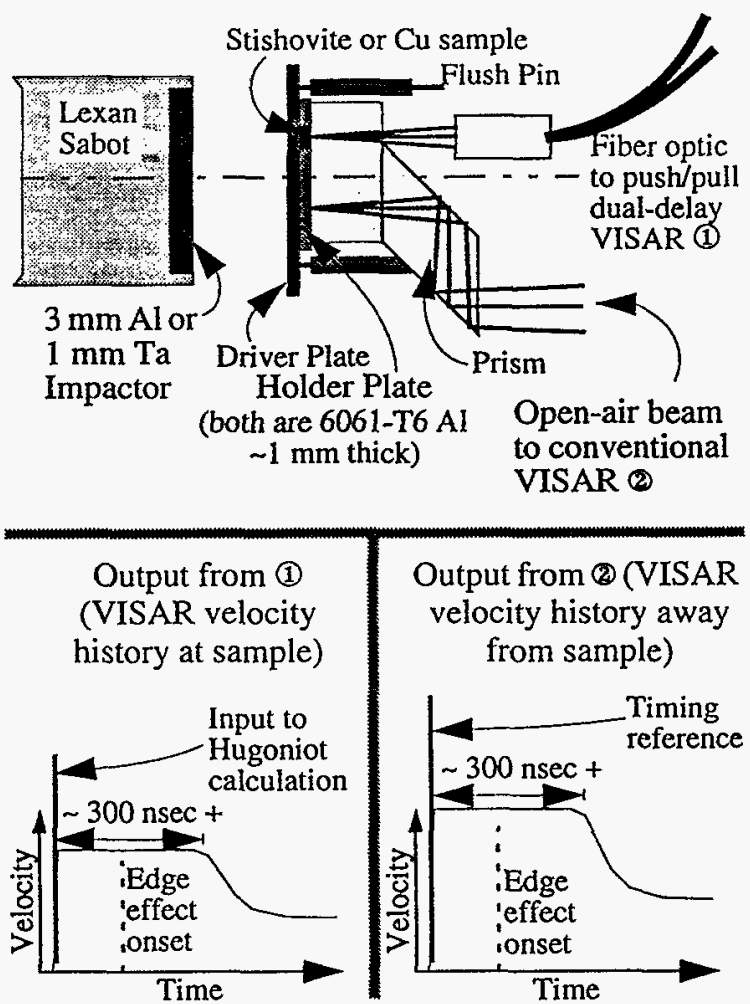

FIGURE 3. Forward-ballistic configuration. 


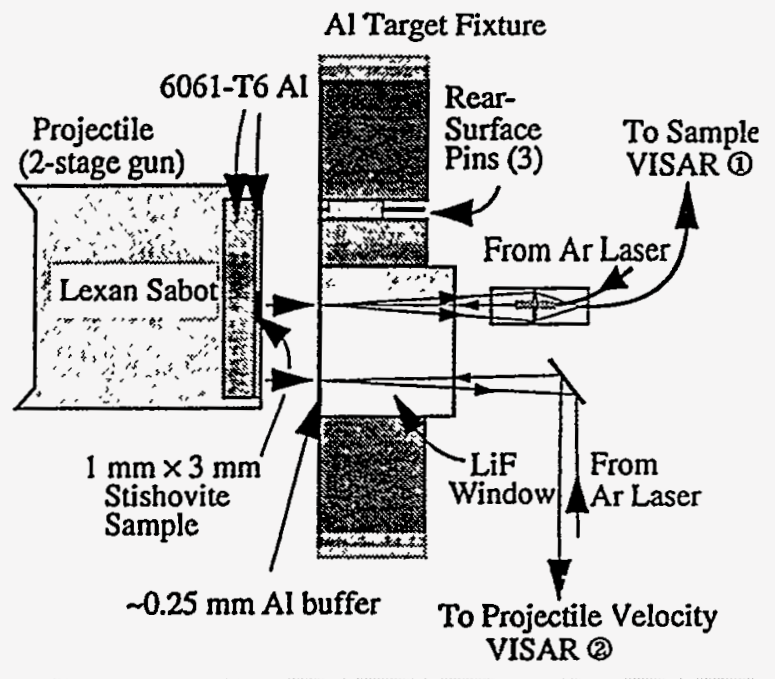

Output from (1) (VISAR Velocity History at Sample Impact Point)

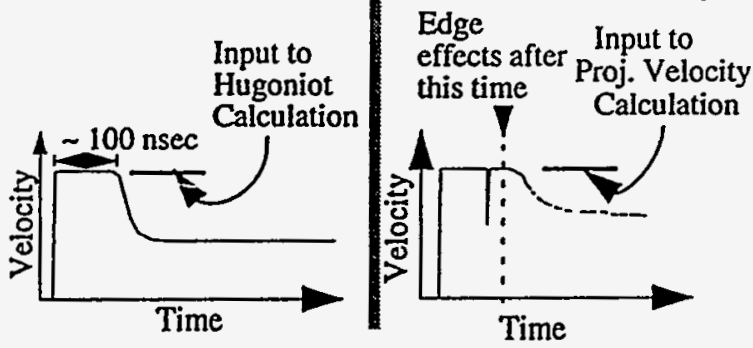

FIGURE 4. Configuration of reverse-ballistic stishovite tests

The primary difficulties for the forward-ballistic tests lay in obtaining a precise (2-3 ns) transit time, done by a careful time correlation of the two VISAR signals. The reverse-ballistic tests proved to be unreliable in delivering the sample to the proper point on the target, and in turn generating acceptable waveforms for both velocity interferometers.

\section{TABLE 1. Test matrix}

\begin{tabular}{lcccc} 
Test & ST2* & ST11 & ST12 & ST13 \\
\hline Projectile. Vel. $(\mathrm{km} / \mathrm{s})$ & 4.01 & 4.88 & 4.98 & 6.54 \\
Impactor Material & - & Al & Ta & Ta \\
Impactor Thickness (mm) & - & 2.995 & 1.030 & 0.779 \\
Sample measurements - & & & & \\
$\quad$ Thickness $(\mathrm{mm})$ & 0.859 & 0.931 & 0.978 & 0.977 \\
$\quad$ Diameter $(\mathrm{mm})$ & 2.40 & 3.600 & 3.700 & 3.872 \\
$\quad$ Density $\left(\mathrm{Mg} / \mathrm{m}^{3}\right)$ & 4.067 & 3.959 & 3.954 & 3.833
\end{tabular}

*Reverse-ballistic test; sample backed by $160 \mu \mathrm{m}$ epoxy.

\section{RESULTS}

Hugoniot results for the four successful tests are summarized in Table 2, and plotted in Figures 5 and 6. The results from the two methods seem to be mutually consistent, and are in substantial agreement with earlier quartz-centered Hugoniot data and with theoretical predictions. The primary source of uncertainty for the forward-ballistic tests is the tilt of the projectile.

The diamond-cell data ${ }^{6}$ probably slightly underestimate density because of the axial X-ray diffraction

TABLE 2. Stishovite Hugoniot states*

\begin{tabular}{lrrrr} 
Test \# $\rightarrow$ & \multicolumn{1}{c}{ ST2 } & \multicolumn{1}{c}{ ST11 } & \multicolumn{1}{c}{ ST12 } & \multicolumn{1}{c}{ ST13 } \\
\hline Strain & $0.16(4)$ & $0.24(3)$ & $0.34(4)$ & $0.33(10)$ \\
$\rho_{0}\left(\mathrm{Mg} / \mathrm{m}^{3}\right)$ & $4.07(30)$ & $3.96(10)$ & $3.95(10)$ & $3.83(10)$ \\
Particle Vel $(\mathrm{k} / \mathrm{s})$ & $1.50(12)$ & $2.06(9)$ & $3.44(8)$ & $4.36(25)$ \\
Stress $(\mathrm{GPa})$ & $59(4)$ & $69(3)$ & $136(9)$ & $223(36)$ \\
$\rho\left(\mathrm{Mg} / \mathrm{m}^{3}\right)$ & $4.8(5)$ & $5.2(3)$ & $6.0(4)$ & $5.7(1.1)$ \\
Shock Vel. $(\mathrm{k} / \mathrm{s})$ & $9.6(1.4)$ & $8.5(7)$ & $10.0(9)$ & $13.4(2.7)$ \\
$\rho / \rho_{0}$ & $1.19(5)$ & $1.32(6)$ & $1.52(10)$ & $1.48(28)$ \\
$V\left(\mathrm{~m}^{3} / \mathrm{Mg}\right)$ & $0.207(19)$ & $0.191(9)$ & $0.166(11)$ & $0.176(28)$ \\
\hline
\end{tabular}

*Figures in parentheses represent uncertainties

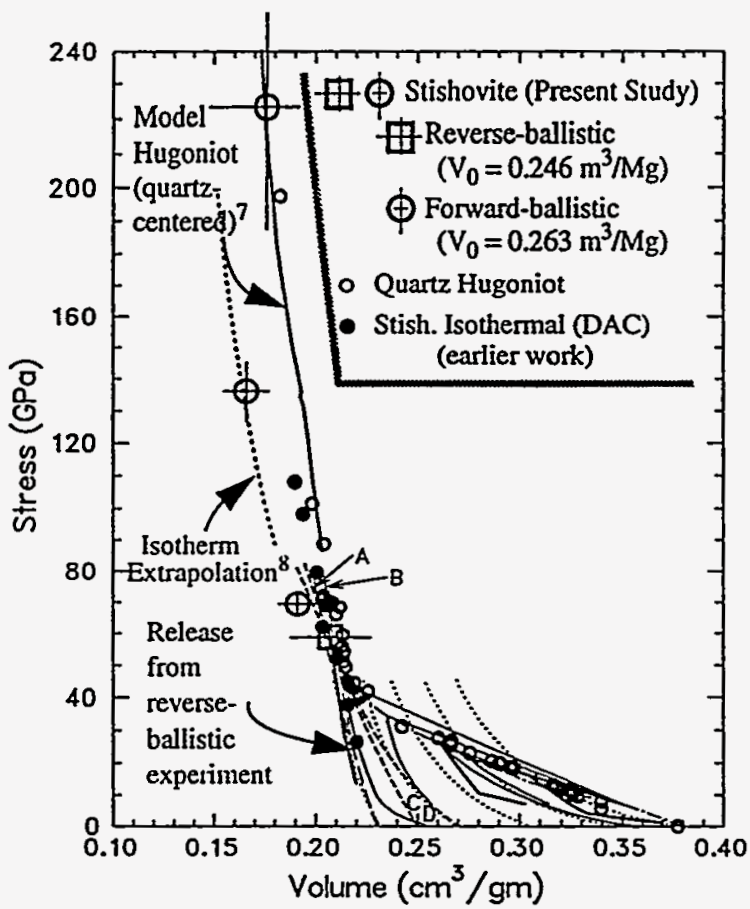

FIGURE 5. Present Hugoniot measurements compared with Fig. 1 curves. Small circles represent an aggregate of previous experiments centered on quart; disks are diamond cell data ${ }^{6}$ 

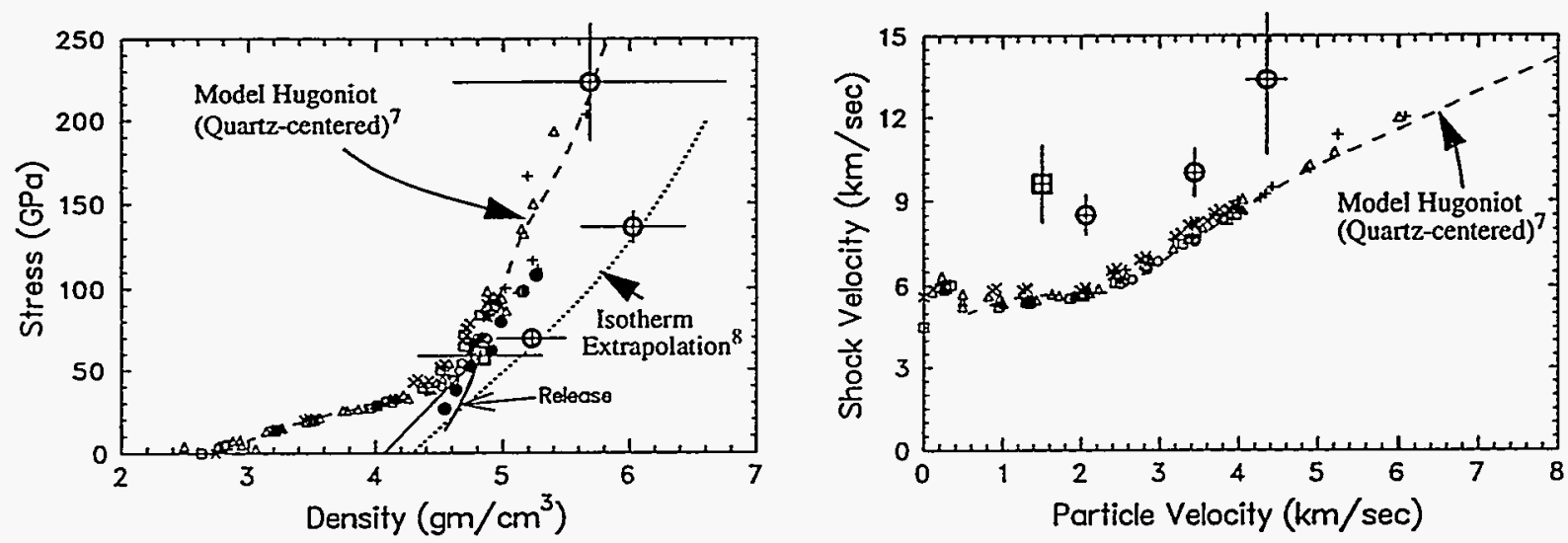

(7) Stishovite Reverse-Ballistic, $\rho_{0}=4.1$

O Single-crystal quartz, $\rho_{0}=2.65$

$\triangle$ Granite, $\rho_{0}=2.66-2.72$

$X$ Anorthosite, $\rho_{0}=2.732$

$\square$ Granite, $p_{0}=2.62-2.63$

+ Gneiss, $\rho_{0}=2.79$

\# Stishovite Forward-Ballistic, $\rho_{0}=3.8$

- Stishovite (Diamond Cell) ${ }^{6}$

FIGURE 6. Hugoniot and release properties of stishovite, compared with representative rock Hugoniot data and stishovite diamond-cell data.

method used, while the isothermal cubic-anvil static data must be extrapolated from $11 \mathrm{GPa}$ to the present region of interest.

Release paths may be derived from the reverse-ballistic test (Furnish'), and depend primarily on the time-of-arrival of the release in the velocity history. This release is plotted with the Hugoniot data and the theoretical Hugoniots and frozen-phase release isentropes in Figure 5. The corresponding waveform match is shown in Figure 7 (WONDY V with custom hysteresis model). Other calculated paths in Figure 7 show that the release inferred from this method is not seriously affected by edge effects.

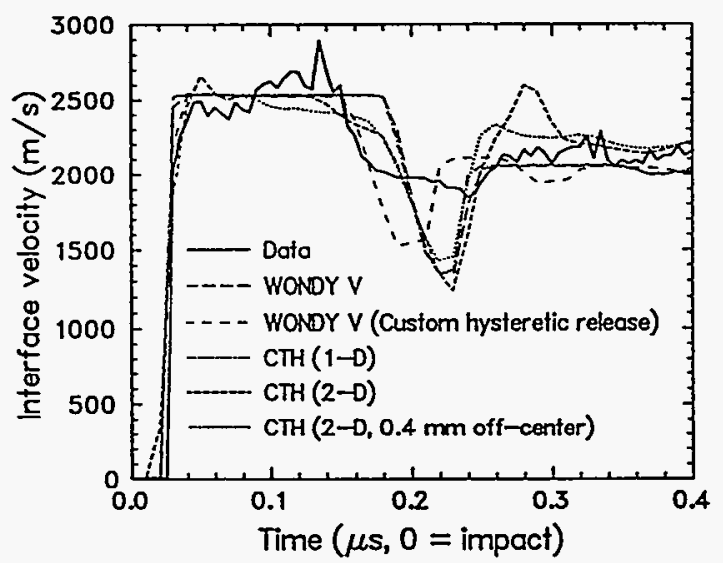

FIGURE 7. Waveform from ST2 reverse-ballistic test, compared with simulations from WONDY V and CTH codes. All simulations used Mie-Grüneisen EOS unless specified.

\section{ACKNOWLEDGEMENTS}

We are very happy to acknowledge the aid of Hideyuki Fujisawa (U of Tokyo) who coordinated the sample synthesis, and Ron McIntosh who headed up shot preparation and performance. This work was sponsored by the USDOE and the Defense Nuclear Agency under contract DE-AC04-94AL85000.

\section{REFERENCES}

1. Wackerle, J., Shock wave compression of quartz, J. Appl. Phys., 33, 922-937, 1962.

2. McQueen, R. G., J. N. Fritz and S. P. Marsh, On the equation of state of stishovite, J. Geophys. Res., 68, 2319-2322, 1963.

3. Grady, D. E., W. J. Murri and G. R. Fowles, Quartz to stishovite: wave propagation in the mixed phase region, $J$. Geophys. Res., 79, 332-338, 1974.

4. Anderson, D. L. and H. Kanamori, Shock wave EOS for rocks and minerals, J. Geophys. Res., 73, 6477-6502, 1968.

5. Chhabildas, L. C. and J. M. Miller, Release-adiabat measurements in crystalline quartz, Sandia National Laboratories Report, SAND85-1092, 1985.

6. Tsuchida, Y. and T. Yagi, A new, post-stishovite high-pressure polymorph of silica, Nature, 340, 217-220, 1989.

7. Boettger, J. C., New model for the shock-induced $\alpha$-quart $z \rightarrow$ stishovite phase transition in silica, J. Appl. Phys., 72, 55005508,1992 . Model Hugoniot is good fit to quartz-centered data.

8. Sato, Y., Pressure-volume relationship of stishovite under hydrostatic conditions, Earth Planet. Sci. Lett, 34, 307-312, 1977 (based on hydrostatic data over 0 - $11 \mathrm{GPa}$ range).

9. Fumish, M. D., Recent advances in methods for measuring the dynamic response of geological materials to $100 \mathrm{GPa}$, Int. J. Impact Engrg., 14, 267-278, 1993. 